\title{
The Turn-Of-The-Month Effect In The S\&P 500 (2001-2011)
}

\author{
Lan Liu, California State University Sacramento, USA
}

\begin{abstract}
This paper investigates if the turn-of-the-month effect exists in the broad US equity market from January 2001 to December 2011 and if applying the knowledge of the "turn-of-the-month" effect to move the dates of investment without engaging active trading strategies can improve the investment performance during the same period of time. We find that the turn-of-the-month effect still exists, but its occurrence has moved to earlier dates. We also find that investment made on days before the turn-of-the-month performs better than those made during the turn-of-the-month. Simple time diversification strategy of spreading investment throughout the month, which doesn't require a perfect foresight, is also found to generate a better performance.
\end{abstract}

Keywords: Turn-of-the-Month Effect; Return Anomaly; Calendar Effects; Diversification

\section{INTRODUCTION}

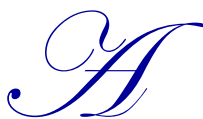

riel (1987) first documents the monthly return anomaly in the US stock market. He finds that stocks exhibit positive returns only around the beginning and during the first half of the calendar months. Lakonishok and Smidt (1988) study this anomaly and find that the period from one trading day before the start of the month until the third day of the month (day -1 to day +3 ) has higher asset returns than the remaining days of the month (ROM). The finance literature names this calendar month return anomaly the turn-ofthe-month (TOM) effect. Subsequent studies find that the TOM effect seems to be persistent across different markets and asset classes. A number of studies also find the TOM effect exploitable.

This paper extends the earlier studies using the latest data to study if the TOM effect still exists in the broad US equity market from January 2001 to December 2011. A discovered return anomaly typically disappears quickly in an efficient market. Hence, the persistency of an anomaly has important implications for market efficiency. We also investigate if this TOM effect is exploitable. In particular, we study if investors can have better returns over the same period of time when they apply the knowledge of the TOM effect and move the investment away from the TOM period. Two scenarios, neither of which requires active trading or switching strategies, are discussed in the paper. In the first scenario, investors choose a specific investment date outside the TOM period; and in the second scenario, investors diversify through time by spreading the investment evenly in days of the month outside the TOM period.

Using the daily data of the S\&P 500 index fund SPY, we find that the TOM effect still exists in the US equity market but the dates of its occurrence have moved earlier. We also find that investors have better returns during the same period of time when they apply the TOM effect knowledge and avoid investing during the TOM period using simple methods that do not require active trading or switching activities. Their investment performance is statistically significantly better than those made during the TOM period.

\section{LITERATURE REVIEW}

Using the Center for Research in Security Prices (CRSP) value-weighted and equally-weighted stock index returns from 1963 to 1981, Ariel (1987) finds that the mean return for stocks is positive only for days immediately before and during the first half of calendar months and indistinguishable from zero for days during the last half of the month. Lakonishok and Smidt (1988) test over 90 years of daily data on the Dow Jones Industrial Average from 
1897 to 1986 and find that the average returns are especially high for the TOM days of -1 to +3 . The cumulative rate of increase over this four days period is 0.473 percent, whereas for an average four-day period, the rate of increase is only 0.0612 percent.

Subsequently, Jacobs and Levy (1988), Ziemba (1989, 1991), Jordan and Jordan (1991), and Hensel, Sick and Ziemba (1994) document evidences of the persistent TOM effects in both the US and international markets and among different asset classes. More recently, McConnell and Xu (2008) find that the TOM effect in US equities is very powerful for the period of 1926 to 2005. Dzhabarov and Ziemba (2010) find that the TOM effect exists for the period of 1993 to 2009 but the days of occurrence change due to the anticipation of the effect. A few studies find that the TOM effect has disappeared. Maberly and Waggoner (2000) find that the TOM effects disappear after 1990 for both the S\&P 500 spot and futures markets. Nikkinen, Sahlstrom and Aijo (2007) find that the significant TOM effect in the S\&P 100 vanished after taking important macroeconomic news announcement into account for the period from 1995 to 2005 .

A major strand of the TOM literature studies the exploitation of the TOM effect. The general consensus is that a switching strategy, which involves moving money between a stock market index and a cash account to take advantage of the TOM effect, outperforms a simple buy-and-hold strategy on the stock market index. Henzel and Ziemba (1996) report a trading strategy that achieves superior performance by switching between an interest bearing cash account and the S\&P 500 Index around the turn-of-the-month. They find that the switching strategy has consistently beaten the buy-and-hold strategy in the S\&P 500 index with higher returns and lower standard deviations. Kunkel and Compton (1998) find that by applying knowledge of the TOM effect investors will improve the risk-adjusted performance of their retirement accounts by using a switching strategy on a money market account and a broad market indexed stock account offered by TIAA-CREF.

A few studies provide insights to help explain the causes of the TOM effect. Among them, Ogden (1987, 1990) suggests that the standardization of payments and the resulting concentration of cash flows at the beginning of the calendar month, where investors realize substantial cash receipts and increase their demand for investment at that time, is responsible for the asset prices to appreciate during the period of time. Other possible explanations include portfolio rebalancing (Haugen and Lakonishok, 1987; Ritter and Chopra, 1989) and the timing of the news announcement as Penman (1987) points out that there is a cluster of positive announcement around the first half of each month while negative news tend to be suppressed until later.

\section{DATA AND METHODOLOGY}

We use the Standard \& Poor's Depository Receipts S\&P 500 exchange-traded fund (ETF), which is also known as SPY after its NYSE ticker symbol, to study the TOM effect in the broad US stock market. SPY was first introduced in 1993 and is now the largest ETF in the world. It provides investors with low cost exposure to the broad market performance compared to other actively managed investment products. We use the CRSP daily closing price of the SPY to calculate daily returns and units that can be purchased on different days of the month. Our study covers the period from January 2001 to December 2011. For each month, we study 20 trading days - ten days before and ten days after the first trading day of each month.

We first study the average daily returns of different trading days and the average cumulative returns of different time periods of the month following the methodology in the previous studies to investigate the monthly return patterns and analyze if the TOM effect exists. We then investigate if buy-and-hold investors can improve their performance by applying the knowledge of TOM effect and scheduling investment purchase orders on a particular day(s) of the month. For the purposes of comparing our results with those in the previous literature, we define the TOM period as day -1 to +4 .

We assume that investors make regular monthly investment purchases of SPY, using the same amount of money $(\$ 1,000)$ and on the same trading day of their choice each month. In the case where investors spread investment across the trading days of the months, approximately $\$ 67(\approx \$ 1,000 / 15)$ is invested on each of the fifteen trading days that are outside of the TOM period. The purchase orders are executed at the closing price of the chosen trading days. We also assume that dividends received are left in a separate cash account and not reinvested in the 
SPY. In unreported results, we study the SPY dividend history and find that investors receive the same amount of dividends at the end of our study period regardless of their chosen trading dates. Thus, the difference in investors' terminal wealth is entirely due to the difference of the SPY units purchased on different trading days of each month. We analyze the SPY units that the investors have at the end of each month and the entire holding period to study if they are statistically significantly more than the ones that investors can have if they have invested during the TOM period.

\section{RESULTS}

\section{Return Patterns: Daily and Cumulative}

Figure 1 shows the average daily returns of different trading days as well as the average of all trading days of the month for the period from January 2001 to December 2011. We find two extended periods of negative returns for five to six days: one from day -10 to -5 and the other from day +3 to +7 . On the other hand, positive returns continue over a much shorter period of only two to three days: day -4 to -2 , day +1 to +2 , and day +8 to +9 .

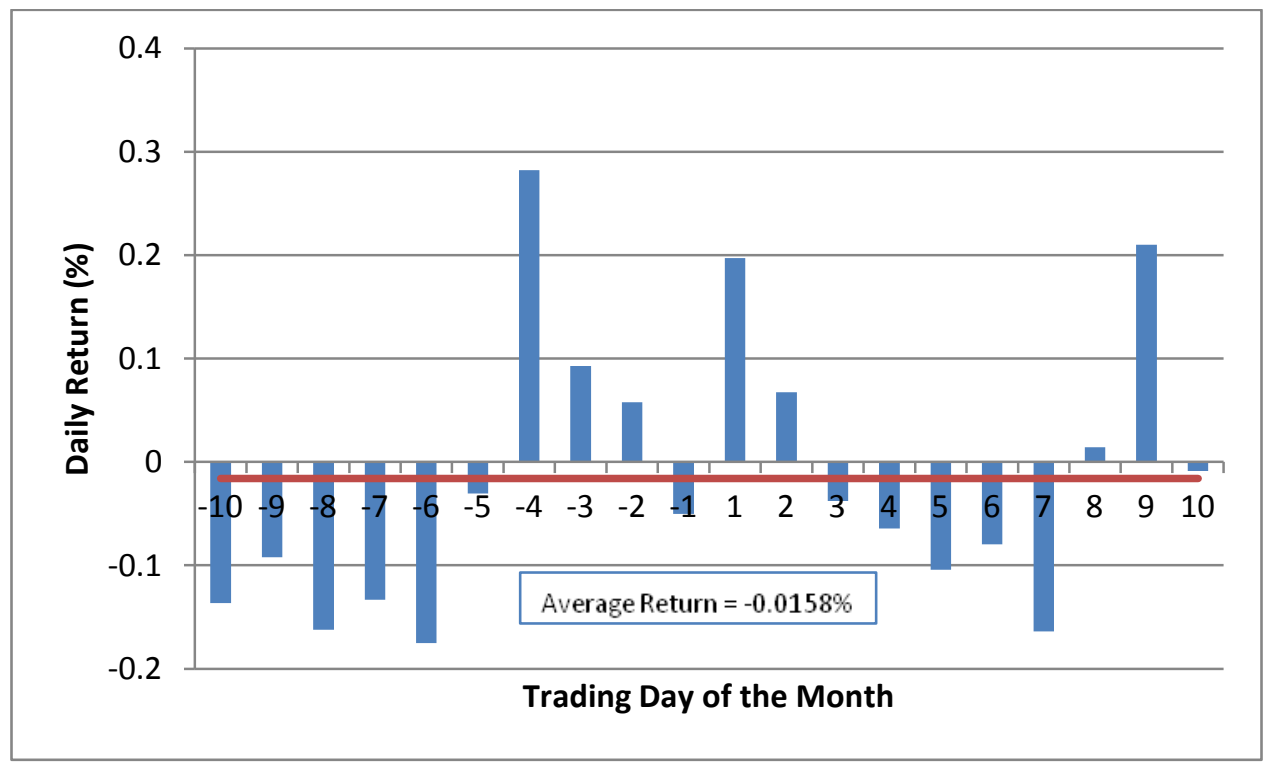

Figure 1: Average Daily Returns By Trading Days Of The Month

Notes: The returns are the log returns of actual daily closing prices without considering the effect of dividends. "Average Return" is the average returns of all 20 trading days of the month.

Historically, the TOM effect is often observed from day -1 to +4 . Such a pattern does not seem to have happened during our sample period. We can regard day -4 to +2 as one period of continuous stretch of positive returns if we ignore the negative return in day -1. In other words, an effect that is similar to the traditional TOM effect in our study begins on "day -4 " and extends through "day +2 ". Thus, the TOM effect seems to have occurred in earlier days in the 2000s compared to its occurrences during prior time periods that were documented in the literature. We call this the Early TOM effect.

Table 1 reports the average daily returns of the five time periods that are of particular interest - three time periods that we have identified in Figure 1 with extended positive and negative returns, the traditional TOM period, and the Early TOM period. Also reported in Table 1 are the differences of the returns in these periods with those of the respective remaining days of the month (ROM) and the entire month.

We find that the results for the Early TOM period of day -4 to +2 are all statistically significantly different from zeros and none of the results for the traditional TOM period of day -1 to +4 are. The average daily return during our Early TOM period is 0.1079 percent while the average daily return for the respective remaining days of 
the month is -0.0689 percent. This represents a daily return difference of 0.1767 percent, or an annualized compound return difference of approximately 56 percent between the average return during the Early TOM period and the ROM. These results are generally consistent with those documented in the earlier literature. For example, the average daily returns for the TOM period and ROM period reported, respectively, in Odgen (1990) for the CRSP value-weighted index are $0.1283 \%$ and $0.0159 \%$; in Henzel and Ziemba (1996) for the S\&P 500 index are 0.1236\% and -0.0235\%; in Kunkel and Compoton (1998) for S\&P 500 account are 0.1596\% and 0.0159\%; and in McConnell and $\mathrm{Xu}$ (2008) for the CRSP value-weighted market return are $0.15 \%$ and $-0.001 \%$. Our findings clearly indicate that the TOM effect still exists, even though the days of its occurrence have been moved earlier.

Table 1: Average Daily Returns (\%) Of Different Periods

\begin{tabular}{|c|c|c|c|c|c|}
\hline Days & Description & Average & ROM & Difference (ROM) & Difference (Month) \\
\hline \multirow[t]{2}{*}{-4 to -2} & Positive returns & $\mathrm{0.1443}^{*}$ & -0.0441 & 0.1884* & $0.1602 *$ \\
\hline & & $(2.0343)$ & $(-1.7305)$ & $(2.2805)$ & $(2.2805)$ \\
\hline \multirow[t]{2}{*}{-10 to -5} & Negative returns & $-0.1216 *$ & 0.0295 & $-0.1511^{*}$ & $-0.1057 *$ \\
\hline & & $(-2.6610)$ & $(1.0854)$ & $(-2.6055)$ & $(-2.6055)$ \\
\hline \multirow[t]{2}{*}{+3 to +7} & Negative returns & -0.0899 & 0.0089 & -0.0988 & -0.0741 \\
\hline & & $(-1.6414)$ & $(0.4016)$ & $(-1.6418)$ & $(-1.6418)$ \\
\hline \multirow[t]{2}{*}{-4 to +2} & Early TOM & 0.1079* & $-0.0689 *$ & $0.1767 *$ & $\mathbf{0 . 1 2 3 7} *$ \\
\hline & & $(2.4078)$ & $(-2.3449)$ & $(2.9205)$ & $(2.9205)$ \\
\hline \multirow[t]{2}{*}{-1 to +4} & TOM & 0.0224 & -0.0286 & 0.0510 & 0.0382 \\
\hline & & $(0.4612)$ & $(-1.2567)$ & $(0.9492)$ & $(0.9492)$ \\
\hline
\end{tabular}

Notes: "ROM" refers to the remaining days of the month that are not covered in the respective periods. $t$ statistics tests the hypothesis that the average return or return difference in the row above is not significantly different from zero. Significance is indicated at 5 percent level with "*”.

We also find that the average daily return during day -4 to -2 is positive and statistically significantly different from zero, from the remaining days of the month, and from the monthly average; similar results are obtained for the negative average daily return during day -10 and -5 . These findings confirm the return patterns shown in Figure 1 and provide additional evidence that the SPY prices advance on days leading to the turn of the month and positive returns are achieved during the Early TOM period while the days leading to the Early TOM period take the most significant portion of the losses for the ROM.

Table 2: Cumulative Returns (\%) Of Different Periods

\begin{tabular}{|c|c|c|c|c|c|}
\hline Days & Description & Cumulative & ROM & Difference (ROM) & Difference (Month) \\
\hline \multirow[t]{2}{*}{-4 to -2} & Positive returns & $0.4330 *$ & -0.7498 & $1.1828 *$ & 0.7498 \\
\hline & & $(2.0343)$ & $(-1.7305)$ & $(2.1911)$ & $(1.7305)$ \\
\hline \multirow[t]{2}{*}{-10 to -5} & Negative returns & $-0.7295 *$ & 0.4127 & $-1.1422 *$ & 0.4127 \\
\hline & & $(-2.6610)$ & $(1.0854)$ & $(-2.2198)$ & $(1.0854)$ \\
\hline \multirow[t]{2}{*}{+3 to +7} & Negative returns & -0.4497 & 0.1329 & -0.5826 & -0.1329 \\
\hline & & $(-1.6414)$ & $(0.4016)$ & $(-1.3211)$ & $(-0.4016)$ \\
\hline \multirow[t]{2}{*}{-4 to +2} & Early TOM & 0.6471* & $-0.9639 *$ & $1.6110 *$ & 0.9639* \\
\hline & & $(2.4078)$ & $(-2.3449)$ & $(2.9040)$ & $(2.3449)$ \\
\hline \multirow[t]{2}{*}{-1 to +4} & TOM & 0.1120 & -0.4288 & 0.5408 & 0.4288 \\
\hline & & $(0.4612)$ & $(-1.2567)$ & $(1.2886)$ & $(1.2567)$ \\
\hline
\end{tabular}

Notes: Same notations as those used in Table 1 except the numbers represent cumulative returns. Average cumulative return for the month is -0.3168 percent.

We continue to examine the cumulative returns of the above trading day periods. Table 2 reports the cumulative returns of the various time periods and their differences with the respective remaining days of the month and the entire month. We find that the cumulative returns for day -4 to -2 and day -10 to -5 are still statistically significantly different from zero from the remaining days of the month and from the entire month. Results for the traditional TOM and the Early TOM periods are consistent with those in Table 1. The average cumulative return for the Early TOM period is 0.6471 percent; the remaining days of the month have an average cumulative return of -0.9639 percent; the difference of the two is 1.6110 percent, all statistically significant. None of the results for the traditional TOM period is statistically significant. The results of the cumulative returns provide further support to our earlier findings that the TOM effect exists and its occurrence has moved to earlier days. 


\section{Units: Investment Performance by Trading Days}

Figure 2 reports the investment performance in terms of terminal wealth in the form of total numbers of units held at the end of the holding period for investment purchases made on different days of the month as well as for the investment that is spread out through the month. We assume that $\$ 1,000$ is invested in SPY on the same trading day of choice each month (and $\$ 67(\approx \$ 1,000 / 15)$ for every trading day outside the TOM period for the case of the diversified investment). All SPY units purchased are held until the end of the period of our study.

Figure 2 shows that investors have the most numbers of SPY units if they buy SPY on day -6 or -5 each month, and much less if they buy on day +2 or +3 . This is consistent with the earlier result that the negative return period stretches from day -10 to -5 and the positive return period stretches from day -4 to -2 . Prices would have been lower prior to day -4 when returns start to turn positive. As a result, we can purchase more units on day -6 and -5 . The Early TOM period ends on day +2 , hence prices continue to increase until day +2 before they start to drop again. Therefore, on average, we purchase the least amount of units on day +2 . We also see that the number of units increase afterwards again until day +7 , which is consistent with the end of the other negative return period of day +3 to +7 . Figure 2 also shows that even though diversifying the investment throughout the trading days of the month does not yield the best performance, it is still better than investment made during the TOM period.

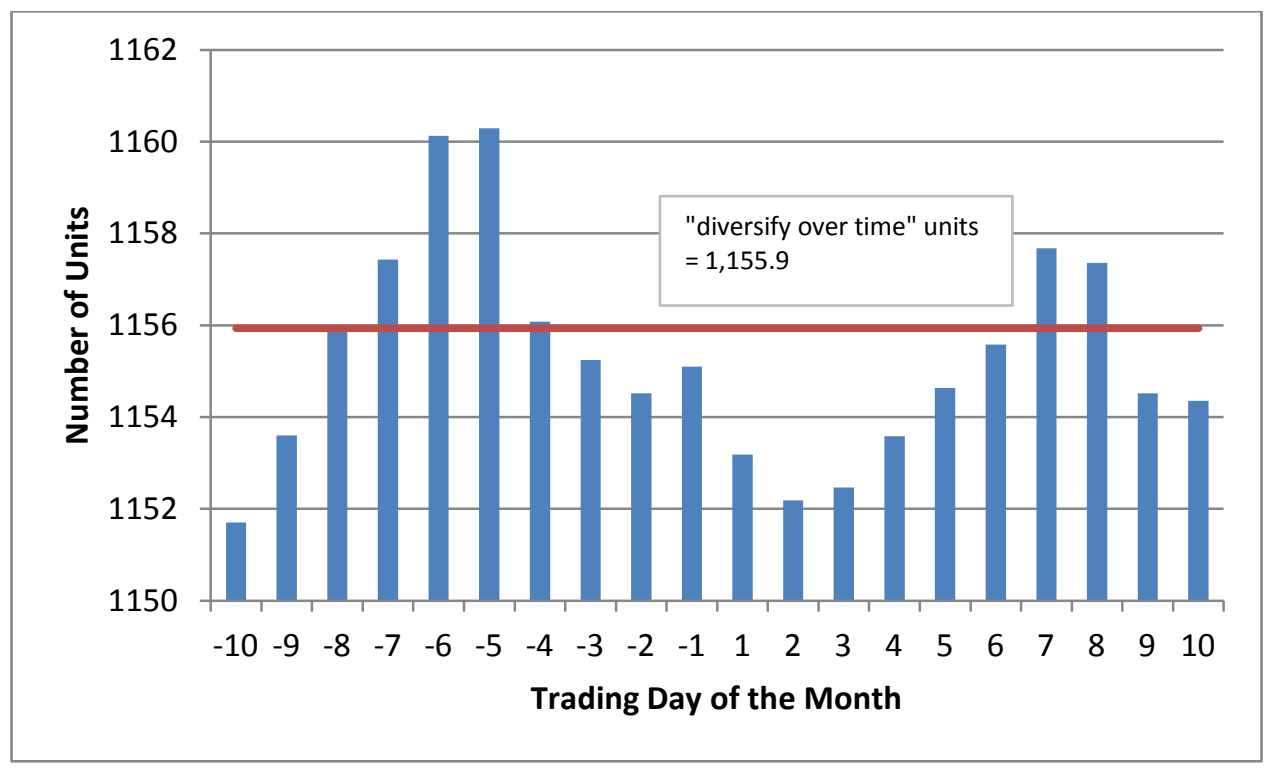

Figure 2: Total Numbers Of Units By Trading Days Of The Month

We further analyze if the units purchased each month are statistically different. Table 3 reports an excerpt of the average percentage differences of the units purchased monthly on different days. Day -6 and -5 have more total units and day $+1,+2$ and +3 have less total units. "Diversify" refers to the diversification strategy where the investment is equally divided on days outside the TOM period. We see that there are statistically significant differences between the units purchased on day -6 and -5 , and day $+1,+2$ and +3 , with the largest difference between day -5 and +2 as Figure 2 predicted. The time diversification strategy also yields more units than the days +2 and +3 with statistical significance. In addition, the number of units purchased on day -6 or -5 is not found to be statistically significantly more than that of a simple time diversification strategy. Our findings thus show that investors who use the knowledge of the TOM effect to avoid making investment during the TOM period do better during the period of the 2000s. In particular, investment made on day -6 or -5 and investment that is diversified through time on days that are outside the TOM period perform better than those made during the TOM period. 
Table 3: Differences Of Units Purchased Monthly

\begin{tabular}{|l|c|c|c|}
\hline \multicolumn{1}{|c|}{ Day } & \% Unit Difference & Stdev & t-stats \\
\hline "-6" vs "+1" & $\mathbf{0 . 5 8 9 1 *}$ & 2.7955 & 2.4213 \\
\hline "-6" vs "+2" & $\mathbf{0 . 6 7 2 9} *$ & 3.3175 & 2.3303 \\
\hline "-6" vs "+3" & $\mathbf{0 . 6 3 8 4} *$ & 3.4362 & 2.1344 \\
\hline "-5" vs "+1" & $\mathbf{0 . 6 1 8 7 *}$ & 2.7804 & 2.5565 \\
\hline "-5" vs "+2" & $\mathbf{0 . 6 9 8 0} *$ & 3.1637 & 2.5348 \\
\hline "-5" vs "+3" & $\mathbf{0 . 6 6 0 9 *}$ & 3.1850 & 2.3841 \\
\hline "diversify" vs "+1" & 0.3067 & 2.0200 & 1.7444 \\
\hline "diversify" vs "+2" & $\mathbf{0 . 3 7 4 7 *}$ & 2.1482 \\
\hline "diversify" vs "+3" & $\mathbf{0 . 3 3 4 4 *}$ & 2.0040 \\
\hline "-6" vs "diversify" & 0.2893 & 1.9010 & 2.0209 \\
\hline "-5" vs "diversify" & 0.3145 & 2.2911 & 1.4505 \\
\hline
\end{tabular}

\section{CONCLUSIONS}

The finance literature has documented a turn-of-the-month (TOM) return anomaly where asset returns for the period from one trading day before the start of the month to the fourth day of the month are found to be higher than those from the remaining days of the month. This paper investigates if the TOM effect exists in the broad US equity market from January 2001 to December 2011 and if applying the knowledge of the TOM effect and taking simple actions to avoid making investment during the TOM period can improve the investment performance.

Using the daily data of the S\&P 500 index fund SPY, we find that the SPY prices advance on days leading to the turn of the month starting from day -4 , which is earlier than the day -1 that is documented in the TOM literature. The period from day -4 to +2 , which we call the Early TOM period, has statistically significantly higher average daily return and cumulative return than any other time periods of the month. Our findings suggest that the TOM effect still exhibits in the US equity market in the 2000s but its occurrence has moved to earlier days, possibly due to the knowledge and anticipation of the effect. Why the TOM effect still lingers around remains a puzzle.

We also find that the SPY prices are typically at the highest level of each month around day +1 and +2 and at the lowest level around day -6 and -5 . Investment in SPY made on day -6 or -5 each month in the first decade of 2000s have higher terminal wealth in the form of more SPY units held than investment made on any other days of the month, especially those during the TOM period. The differences are statistically significant. The simple time diversification strategy, where equal amount is invested on days outside the TOM period, is also found to do better than investment made during the TOM period.

Replicating the superior investment performance by investing on day -6 or -5 or trying to identify a new best date to invest is difficult, especially when the dates of actual TOM effect changes upon the anticipation of the effect. However, we show that even without the foresight or perfect predicting ability, investors can still achieve a better performance by spreading the investment throughout the month. For investors who have access to some no transaction cost retirement accounts, it seems to be a good idea to adopt such a strategy to avoid the TOM effect or other calendar month anomalies that may possibly occur during any time period of the month.

\section{AUTHOR INFORMATION}

Dr. Lan Liu is an Assistant Professor of Finance at the College of Business Administration at the California State University Sacramento. Her research interests include investment portfolio management, risk forecasting and performance measurement. E-mail: $\underline{\text { liul@csus.edu }}$

\section{REFERENCES}

1. Ariel, R.A. (1987). A Monthly Effect in Stock Returns. Journal of Financial Economics, 18, 161-174.

2. Compton, W.S. \& Kunkel, R.A. (2000). Tax-Free Trading on Calendar Stock and Bond Market Patterns. Journal of Economics and Finance, 24 (1) 64-76. 
3. Dzhabarov, C. \& Ziemba, W.T. (2010). Do Seasonal Anomalies Still Work? Journal of Portfolio Management, 36 (3) 93-104.

4. Hensel, C.R. \& Ziemba, W.T. (1996). Investment Results from Exploiting Turn-of-the-Month Effects: Should You Pay Attention to the Turn of the Month? Journal of Portfolio Management, 22 (3) 17-23.

5. Hensel, C.R., Sick, G. \& Ziemba, W.T. (1994). The Turn of the Month Effect in the S\&P 500, 1926-1992. Review of Futures Markets, 13 (3) 827-856.

6. Jacobs, B.I. \& Levy, K.N. (1988). Calendar Anomalies: Abnormal Returns at Calendar Turning Points. Financial Analyst Journal, 44 (6) 28-39.

7. Jordan, S.D. \& Jordan, B.D. (1991). Seasonality in Daily Bond Returns. Journal of Financial and Quantitative Analysis, 26 (2) 269-285.

8. Kunkel, R.A. \& Compton, W.S. (1998). A Tax-Free Exploitation of the Turn-of-the-Month Effect: C.R.E.F.. Financial Services Review, 7 (1) 11-23.

9. Lakonishok, J. \& Smidt, S. (1988). Are Seasonal Anomalies Real? A Ninety-Year Perspective. Review of Financial Studies, 1 (4) 403-425.

10. Maberly, E.D. \& Waggoner, D.F. (2000). Closing the Question on the Continuation of Turn-of-the-Month Effects: Evidence from the S\&P 500 Index Futures Contract. Federal Reserve Bank of Atlanta. Retrieved from http://www.frbatlanta.org/pubs/wp/working_paper_2000-11-abstract.cfm?printable

11. McConnell, J.J. \& Xu, W. (2008). Equity Returns at the Turn of the Month. Financial Analyst Journal, 64 (2) 49-62.

12. Nikkinen, J., Sahlstrom, P. \& Aijo, J. (2007). Turn of the Month and Intramonth Effects: Explanation from the Important Macroeconomic News Announcements. Journal of Futures Markets, 27 (2) 105-26.

13. Ogden, J.P. (1987). The End of the Month as a Preferred Habitat: A Test of Operational Efficiency in the Money Market. Journal of Financial and Quantitative Analysis, 22 (3) 329-344.

14. Ogden, J.P. (1990). Turn-of-Month Evaluations of Liquid Profits and Stock Returns: A Common Explanation for the Monthly and January Effects. Journal of Finance, 45 (4) 1259-1272. 


\section{NOTES}

